\title{
The decline of ungulate populations in Iranian protected areas calls for urgent action against poaching
}

\author{
Arash Ghoddousi, Mahmood Soofi, Amirhossein Kh. Hamidi, \\ Sheyda Ashayeri, Lukas Egli, Siavash Ghoddousi, Julian Speicher, \\ Igor Khorozyan, Bahram H. Kiabi and Matthias Waltert
}

\begin{abstract}
Poaching is cryptically but rapidly driving many species towards extinction. Knowledge of population trends of exploited species and incentives for poaching is necessary to inform appropriate conservation measures. We estimated the abundance of four ungulate species in Golestan National Park, Iran, the country's oldest protected area, where poaching of ungulates is widespread. We used line transect surveys (186 km), camera trapping (2,777 camera-nights), point counts (64 scans) and dung counts (along $38 \mathrm{~km}$ ), and compared population estimates with those from earlier records. We also investigated the incentives for poaching, using a semi-structured interview survey. Population estimates for 2011-2014 indicated a 66-89\% decline in three ungulate species (bezoar goat Capra aegagrus, red deer Cervus elaphus and urial Ovis vignei) compared to 1970-1978. Only wild boar Sus scrofa showed a population increase (of $58 \%$ ) during the same period, possibly facilitated by religious restrictions regarding the consumption of this species. The incentives for poaching were categorized (in a non-ordinal manner) as subsistence, pleasure, tradition, trade of wild meat, and conflict with conservation regulations and bodies. The decline in hunted ungulates in this Park appears to be the result of rampant poaching, and a similar trend is evident in other protected areas in the country. We suggest the adoption of participatory conservation strategies, improvement of law enforcement practices and cooperation
\end{abstract}

\footnotetext{
Arash Ghoddousi* (Corresponding author), Mahmood Soofi, Lukas EgLi, Igor Khorozyan and Matthias Waltert Workgroup on Endangered Species, J.F. Blumenbach Institute of Zoology and Anthropology, Georg-AugustUniversität Göttingen, Bürgerstr. 5037073 Göttingen, Germany

Amirhossein Kh. Hamidi and Sheyda Ashayeri $\dagger$ Persian Wildlife Heritage Foundation, Tehran, Iran

Siavash GHoddousi Faculty of Economics, Universidade do Algarve, Faro, Portugal

Julian Speicher Department of Wildlife Sciences, Georg-August-Universität Göttingen, Göttingen, Germany

Bahram H. Kiabi Faculty of Biological Sciences, Shahid Beheshti University G.C., Tehran, Iran

*Present address: Conservation Biogeography, Geography Department, Humboldt-Universität zu Berlin, Unter den Linden 610099 Berlin, Germany E-mail arash.ghoddousi@hu-berlin.de

$†$ Present address: Raddepaw Foundation for Rural Development and Biodiversity Conservation, Tehran, Iran

Received 22 June 2016. Revision requested 5 October 2016.

Accepted 10 November 2016. First published online 12 April 2017.
}

with international experts to reduce poaching in these protected areas. Taking into account the incentives for poaching, a combination of economic and non-economic strategies should be considered.

Keywords Golestan National Park, hunting, incentive, Iran, law enforcement, monitoring, poaching, population trend

\section{Introduction}

Doaching is a key phenomenon in the overexploitation of natural resources, driving many species towards extinction (Milner-Gulland et al., 2003). There are various incentives for poaching, which occurs at a variety of scales, from hunting by local communities for subsistence to selling wild meat in urban markets and international trafficking of wildlife or wildlife parts for income generation (Sutherland, 200o). The illegal and cryptic nature of poaching, and a lack of systematic wildlife monitoring schemes, make it difficult to detect population declines from poaching (Singh \& Milner-Gulland, 2011; Nuno et al., 2013), and a lack of information on wildlife trends may hamper timely conservation responses (Milner-Gulland et al., 2003).

Enforcement is probably the most widely practised measure against poaching, and intensification has a positive influence on wildlife (Hilborn et al., 2006; Ghoddousi et al., 2016a). However, enforcement requires social acceptability and proper sanctions to be effective (Milner-Gulland \& Rowcliffe, 2007). Integrated conservation and development projects may therefore be influential in reducing poaching by targeting economic or non-economic incentives, although they may fail if the wrong incentives are targeted (Duffy et al., 2016). Knowledge about incentives for poaching at the local level is required to guide the choice of appropriate conservation measures for reducing poaching pressure (Nuno et al., 2013; Challender \& MacMillan, 2014).

Hunting has a long history in livelihoods and culture in Iran (Firouz, 2005), but with the onset of the 2oth century the availability of off-road vehicles and sophisticated firearms led to wildlife massacres across the country (Firouz, 2005). The Caspian tiger Panthera tigris virgata and Asiatic lion Panthera leo persica have gone extinct in Iran in the past century and the Persian fallow deer Dama 
mesopotamica had been considered to be extinct prior to its rediscovery in 1957 (Firouz, 2005). Wildlife populations declined significantly in most areas until the first modern hunting control was introduced in the 1950s (Moore, 1976; Firouz, 2005).

Regulation of hunting in Iran began in 1956 with the establishment of the Game Council of Iran (renamed the Department of Environment in 1974) and the creation of the first network of protected areas. These efforts initiated recovery of wildlife in some areas (Moore, 1976; Firouz, 2005). Since then the Department of Environment has continued to increase the number of protected areas, and the area under its protection now comprises $>10 \%$ of the country's land (Kolahi et al., 2012). However, political turbulence since 1979, lack of acceptance of conservation laws by local communities and the insufficient resources of the Department of Environment have resulted in widespread poaching in most protected areas (Tatin et al., 2003; Kiabi et al., 2004; Ghoddousi et al., 2016a).

Ungulates are a major target of hunting in Iran (Firouz, 2005), with a diverse range of species, including the bezoar or wild goat Capra aegagrus, chinkara or jebeer gazelle Gazella bennettii, goitered gazelle Gazella subgutturosa, mouflon or wild sheep Ovis orientalis, urial Ovis vignei, onager Equus hemionus onager, Persian fallow deer, red deer Cervus elaphus, roe deer Capreolus capreolus and wild boar Sus scrofa. Six of these species are threatened globally (IUCN, 2016; note synonymy of urial and mouflon on the Red List and the new classification of Rezaei et al., 2010). Apart from the Persian fallow deer, which lives in semicaptive conditions, and the wild boar, the consumption of which is prohibited on religious grounds, all other ungulate species are threatened by poaching and have declined since the 1970s (Karami et al., 2002; Tatin et al., 2003; Kiabi et al., 2004; Shams Esfandabad et al., 2010; Ghoddousi et al., 2016a; Soofi et al., 2017).

Despite widespread poaching, the scale of these declines in Iranian protected areas is unknown, as robust ungulate monitoring techniques are largely lacking. Furthermore, knowledge of the incentives for poaching remains limited. Subsistence, monetary profit, cultural values and conflict with the Department of Environment are the main incentives for poaching of ungulates in Bamu National Park (Ashayeri \& Newing, 2012), but whether this is also the case in other protected areas in Iran is unclear.

We measured ungulate population trends in Golestan National Park, for which ungulate abundance data are available from the 1970s (Decker \& Kowalski, 1972; Kiabi, 1978; Kiabi et al., 2004). We assessed the populations of four species (bezoar goat, red deer, urial and wild boar) and compared them with their earlier status. There is no information on large-scale migrations, diseases or other environmental conditions, which might have affected the populations of these four species during this period
(Ghoddousi et al., 2016b). There is no competition with livestock in this area, as grazing is banned inside the Park and illegal grazing occurs only at a limited scale along the periphery (Ghoddousi et al., 2016b). Moreover, no major habitat destruction or development projects have reduced wildlife habitats in the Park in recent decades. However, poaching has been widely reported as being one of the main threats to ungulate species in the Park (Kiabi et al., 2004; Hamidi et al., 2014; Ghoddousi et al., 2016a; Soofi et al., 2017).

The severity of penalties, likelihood of capture by rangers, and incentives are the most important factors in poaching decisions (Milner-Gulland \& Leader-Williams, 1992). Hunting is illegal in Golestan National Park and incurs fines or imprisonment. The density of rangers in the Park (c. 1 per $29.1 \mathrm{~km}^{2}$; authors, unpubl. data) is deemed sufficient to control illegal activities according to international recommendations (one ranger per $23.8 \mathrm{~km}^{2}$; Jachmann \& Billiouw, 1997). As understanding incentives may help managers find solutions to curb poaching (Milner-Gulland \& Leader-Williams, 1992), we also evaluated the incentives for local poachers of ungulates in the context of existing disincentives.

\section{Study area}

Golestan National Park was established in 1957 in northeastern Iran (Fig. 1). It encompasses Hyrcanian montane forests, steppes and arid plains in an area of $874 \mathrm{~km}^{2}$ (Akhani, 2005). From west to east, elevations span $450-$ $2,411 \mathrm{~m}$, with mean annual precipitation of $866-142 \mathrm{~mm}$, thus creating a variety of habitats (Akhani, 2005). The Park holds six species of ungulates, which is one of the highest numbers of ungulate species in Iranian protected areas (Ghoddousi et al., 2016b). Urial occur in steppes in the east and north of the Park, and roe deer and red deer inhabit forests in western and central parts. Wild boar are present throughout the Park (with the exception of a $25 \mathrm{~km}^{2}$ arid plain), with higher densities in forests. A population of goitered gazelles occupies narrow plains in the east and north. Bezoar goats occur on cliffs across the Park. There are no villages within the Park but there are 15 villages, with c. 8,660 inhabitants, within $2 \mathrm{~km}$ of the Park borders. These communities rely mainly on crop and livestock farming.

\section{Methods}

\section{Estimation of ungulate populations}

We used a variety of methods to estimate population size, depending on the detection probabilities and habitat characteristics of the ungulate species (Ghoddousi et al., 2016b). 


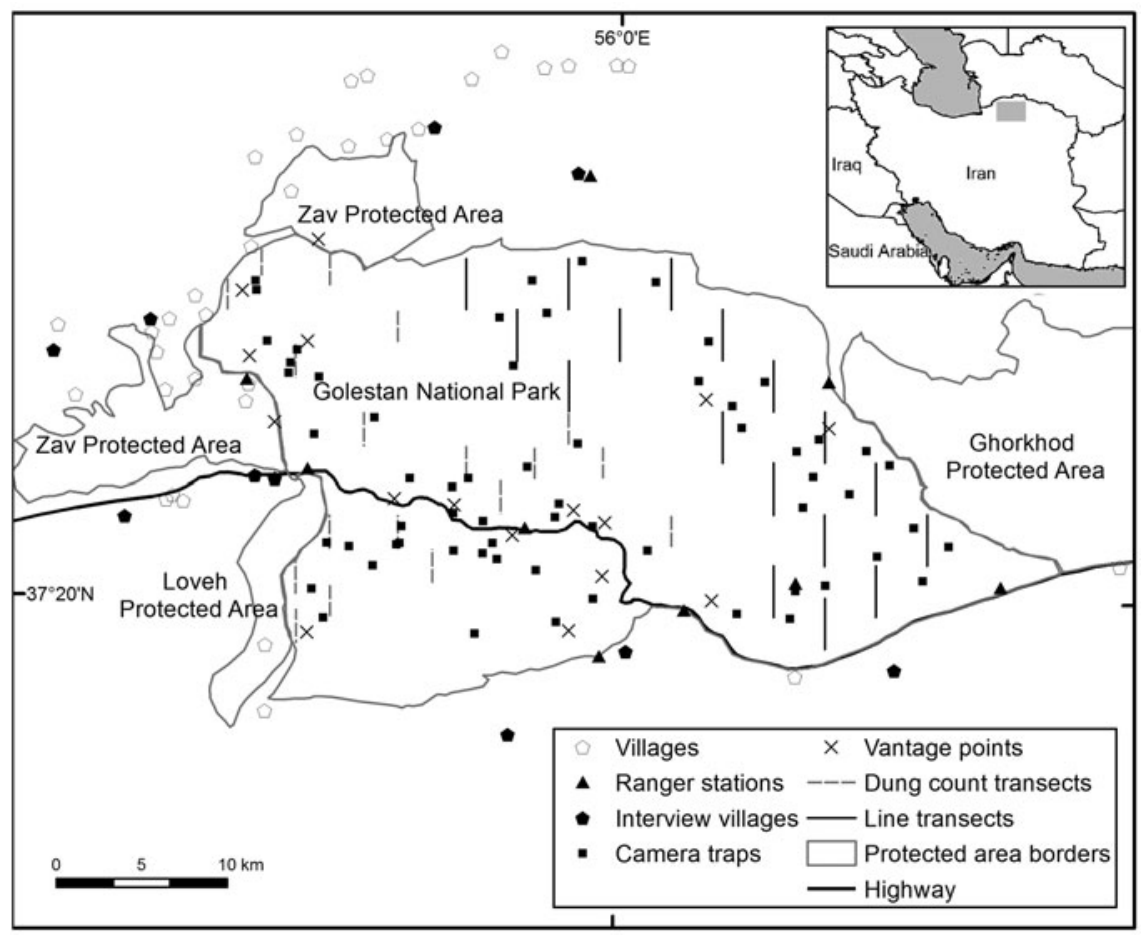

FIG. 1 Locations of line transects, dung count transects, camera traps, vantage points, ranger stations, and villages in and around Golestan National Park, Iran.
We excluded the goitered gazelle and roe deer from our study because the former has a limited distribution in the Park and there are insufficient data on the latter to facilitate estimation. Our estimates of abundance for 2011-2014 were compared to data for 1970-1978, which were based on comparable systematic monitoring methods (Decker \& Kowalski, 1972; Kiabi, 1978; Kiabi et al., 2004). We are not aware of any other studies on populations of these ungulates in the Park during this time frame. When more than one estimate for a given species was available, or if a population range was given, we calculated the arithmetic mean.

Bezoar goat We used a double-observer point count during November-December 2014 to estimate the abundance of bezoar goats (Suryawanshi et al., 2012). We identified $53.6 \mathrm{~km}^{2}$ of rugged landscape as bezoar goat habitat and surveyed 16 sampling points at random within this area, with a minimum distance of $3 \mathrm{~km}$ between two points (Fig. 1). Two observers counted groups of goats, from vantage points $200-500 \mathrm{~m}$ away from the sampling points. The data were analysed using DOBSERV (Nichols et al., 2000). The sampled area was calculated as the overlap of observable areas from vantage points and the identified goat habitat, using the viewshed function in ArcGIS 10.1 (ESRI, Redlands, USA). A detailed description of our sampling and modelling approaches is provided by Ghoddousi et al. (2016b). The earlier estimate of the bezoar goat population in the Park (4,000-4,500) was based on full-day observations in sample areas during 1976-1978 (Kiabi, 1978).
Red deer To estimate the red deer population size we used dung counts (faecal standing crop approach) and camera-trap data (randomized encounter model) in $422 \mathrm{~km}^{2}$ of forests and grasslands (Buckland et al., 2001; Rowcliffe et al., 2008). For the dung counts we estimated red deer defecation rates by observing 20 individuals for 8 days in a $0.02 \mathrm{~km}^{2}$ enclosure with habitat comparable to that in the Park. Prior to the survey we estimated the dung decay rate by monitoring 80 fresh dung samples across red deer habitats in the Park and using binary logistic regression to assess the influence of time and habitat types on the survival of dung samples. We then surveyed 18 strip transects of $2 \mathrm{~km}$ length and $2 \mathrm{~m}$ width across red deer habitats during January-February 2013 (Fig. 1). For the randomized encounter modelling we used data from an earlier study, gathered from 37 camera traps during May-December 2011 (Fig. 1) (Hamidi et al., 2014). We calculated mean group size from observations of 57 red deer groups by park rangers during the period of camera trapping. Given the lack of red deer movement data from Golestan National Park or elsewhere in Iran, we used a mean of daily range estimates from other studies of $3.36 \pm$ SE $0.23 \mathrm{~km}$ per day (Soofi et al., 2017). The camera-related parameters required by the randomized encounter model were obtained from a previous study that used a similar brand of camera trap (Deercam DC30o; Non Typical Inc., De Pere, USA; Rowcliffe et al., 2008). Details of the sampling and the application of both methods are provided by Soofi et al. (2017). Red deer abundance during 1976-1978 was estimated by 
Hahn's census method via line transect surveys, and dung counts, as 1,897 and 2,096 individuals, respectively (Kiabi et al., 2004).

Urial We used line transects to estimate the urial population size in $340 \mathrm{~km}^{2}$ of steppes in the east and north of the Park (Buckland et al., 2001). We surveyed 17 $3-\mathrm{km}$ transects during January-February and AugustSeptember 2013, and February 2014 (Fig. 1), and analysed the data using Distance 6.o (Thomas et al., 2010). A detailed description of the methodology used to estimate the urial population is provided by Ghoddousi et al. (2016a). The urial population in 1970 was estimated by total counts in 12 sampling units and the extrapolation of recorded densities over the steppes of the Park (Decker \& Kowalski, 1972). The estimated abundance was c. 15,000 individuals (Decker \& Kowalski, 1972). In a separate survey that used direct counts on line transects, there were estimated to be 10,000-11,000 urial in the Park during 1976-1978 (Kiabi, 1978).

Wild boar We estimated the abundance of wild boar using randomized encounter modelling based on camera-trap surveys conducted during January-December 2011 (Rowcliffe et al., 2008; Hamidi et al., 2014). We used data from 67 camera traps installed throughout the Park, excluding a $25 \mathrm{~km}^{2}$ arid plain (Fig. 1) (Hamidi et al., 2014). The mean group size was estimated from observations on line transects during 2013-2014 (see above). Given the lack of information on the daily range of this species from the study site, we used an estimate of $6.8 \pm \mathrm{SE} 0.57 \mathrm{~km}$ per day from a study with similar habitat conditions (Podgórski et al., 2013). Details of our study design and analysis are provided by Hamidi et al. (2014) and Ghoddousi et al. (2016b). We used an earlier estimate of 2,500-3,000 wild boar from line transect surveys during 1976-1978 (Kiabi, 1978).

\section{Sensitivity analysis}

To assess the effects of uncertainty in population estimates we conducted sensitivity analysis using various combinations of 95\% confidence intervals (2011-2014) and population ranges (1970-1978) for each species.

\section{Interview survey and arrest records}

Taking into account that poaching is a sensitive subject, we collected data on incentives for poaching by conducting semi-structured interviews with local people (Newing, 2011). We identified poachers in villages in the vicinity of the Park through a process of chain referral (Newing, 2011). Local poachers agreed to participate in the study after we collaborated with them in joint wildlife monitoring programmes (Hamidi et al., 2014; Ghoddousi et al., 2016a), built mutual trust, and explained the purpose of the study to them. Not being affiliated to any governmental organizations facilitated the process of data gathering and communicating with poachers. We asked each individual to give the main reasons for poaching ungulates in the Park (Ashayeri \& Newing, 2012). We encoded and categorized incentives based on similar elements in responses (Ashayeri \& Newing, 2012). We assured interviewees that their data would remain anonymous and interviewees gave their verbal consent to participation in the survey. We held a focus group meeting with five poachers in December 2012 to elicit information about the incentives for poaching. We also used the findings of a social study on poachers in the Park (Ashayeri, 2014), conducting informal qualitative interviews with 15 poachers during June 2013-February 2014. Interviews were continued until data reached the level of saturation, meaning that no further information could be extracted from new interviews (Newing, 2011). Details of the interview procedure and analytical approaches used are in Ashayeri (2014). The interviewees in both studies were all men, 29-66 years old, from 10 villages around the Park (Fig. 1). We also used seizure records for 2007-2014 to assess the frequency of poaching of various species in the Park. We calculated the poaching rate for each species as the number of hunted individuals as a proportion of their population size (2011-2014). As rangers use a sit-and-wait approach or tip-offs from local informants to detect poachers, we believe that seizure data are not biased towards a certain species, and represent the distribution of hunted species in the Park (authors, unpubl. data).

\section{Results}

\section{Population estimation}

Bezoar goat During 64 scans of 15 minutes each we observed 39 bezoar goats in seven groups. The model with equal detection probability between the observers estimated an abundance of 519 individuals (confidence interval $\mathrm{CV}=31.3 \%$; $95 \% \mathrm{CI}=201-807$; Table 1 ). A comparison of recent estimates with the mean population size from 1976 1978 indicates an $88 \%$ decline of the bezoar goat population (Fig. 2). The results of sensitivity analysis show a decline of 79-96\% during this period (Table 1).

Red deer From 1,676 dung samples we estimated a defecation rate of 10.5 dung piles per individual per day. Given the lack of knowledge regarding the variation in defecation rates among red deer individuals it was not possible to calculate the standard error. The age-based model estimated a red deer dung decay rate of $142 \pm$ SE 15 days. Fifty red deer dung samples were detected from a 
TABLE 1 Abundance of four ungulate species in Golestan National Park, Iran (Fig. 1) during 1970-1978 and $2011-2014$.

\begin{tabular}{|c|c|c|c|c|c|}
\hline \multirow[b]{2}{*}{ Species } & \multicolumn{2}{|l|}{$1970-1978$} & \multicolumn{2}{|l|}{ 2011-2014 } & \multirow{2}{*}{$\begin{array}{l}\text { Population change } \\
\text { (sensitivity range) }\end{array}$} \\
\hline & Abundance & Range & Abundance & $95 \% \mathrm{CI}$ & \\
\hline Bezoar goat Capra aegagrus & $4,250^{1}$ & $4000-4,500^{2}$ & 519 & $201-837^{3}$ & $-88 \%(-79$ to $-96 \%)$ \\
\hline Red deer Cervus elaphus & $1,997^{1}$ & $1897-2,096^{4}$ & $226^{1}$ & $91-423^{5}$ & $-89 \%(-78$ to $-96 \%)$ \\
\hline Urial Ovis vignei & $12,500^{1}$ & $10,000-15,000^{2,6}$ & 4,275 & $2,117-8,632^{7}$ & $-66 \%(-14$ to $-86 \%)$ \\
\hline Wild boar Sus scrofa & $2,750^{1}$ & $2,500-3,000^{2}$ & 6,478 & $3,050-9,906^{3}$ & $58 \%(2-75 \%)$ \\
\hline
\end{tabular}

${ }^{1}$ Arithmetic mean of two population estimates/ranges

${ }^{2}$ Kiabi (1978)

${ }^{3}$ Ghoddousi et al. (2016b)

${ }^{4}$ Kiabi et al. (2004)

${ }^{5}$ Soofi et al. (2017), from random encounter models

${ }^{6}$ Decker \& Kowalski (1972)

${ }^{7}$ Ghoddousi et al. (2016a)

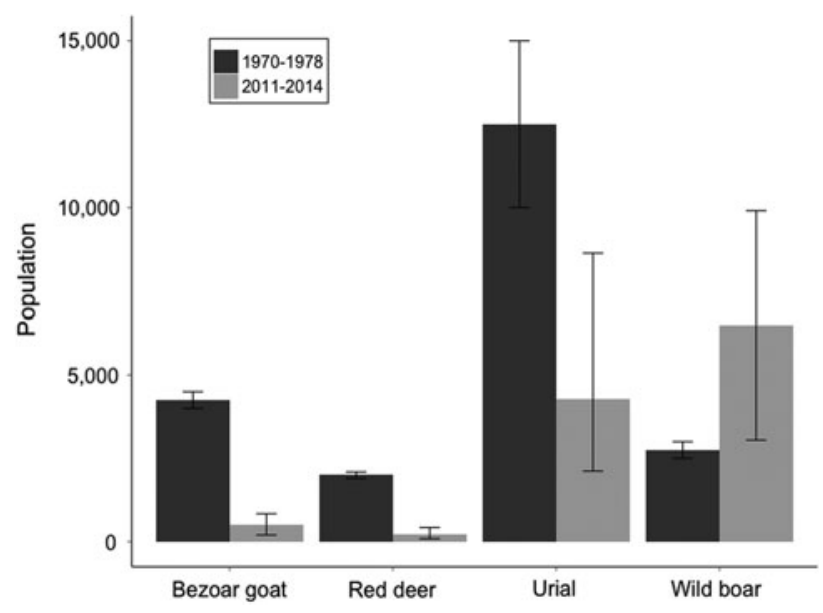

FIG. 2 Comparison of bezoar goat Capra aegagrus, red deer Cervus elaphus, urial Ovis vignei and wild boar Sus scrofa populations in Golestan National Park (Fig. 1) during 1970-1978 and 2011-2014. The error bars represent the $95 \%$ confidence intervals.

survey effort of $36 \mathrm{~km}$. The faecal standing crop method estimated an abundance of 194 red deer $(\mathrm{CV}=28.4 \%$; $95 \%$ $\mathrm{CI}=103-285$; Table 1 ). We captured 10 photographs of red deer from 1,585 camera-nights of effort in forests and grasslands of the Park (Fig. 1). Using the randomized encounter modelling approach we estimated a red deer population of 257 individuals $(\mathrm{CV}=35.3 \%$; $95 \% \mathrm{CI}=91-$ 423; Table 1). Comparison of the mean red deer populations in 2011-2013 and 1976-1978 indicates an 89\% decline (Fig. 2). We used the wider 95\% CI from the randomized encounter model for red deer sensitivity analysis, and the results indicated a decline rate of $78-96 \%$ compared to 1976-1978 (Table 1).

Urial From a total survey effort of $186 \mathrm{~km}$ we observed 1,981 urial in 70 groups. The half-normal key detection function of Distance 6.0 estimated a population of 4,275 individuals $(\mathrm{CV}=35.5 \%$; 95\% CI $=2,117-8,632$; Table 1$)$. Comparison between 2013-2014 abundance estimates and the mean of the two estimates for 1970 and 1976-1978 indicates a $66 \%$ decline in urial abundance (Fig. 2). The results of sensitivity analysis indicated a $14-86 \%$ decline in the urial population (Table 1).

Wild boar From our observations of 38 groups of wild boar on line transects we estimate a mean group size of $3.1 \pm$ SE 0.9 individuals. We captured 386 photographs of wild boar during 2,777 trap-nights across the Park, and using the randomized encounter modelling approach we estimated an abundance of 6,478 individuals $(\mathrm{CV}=27.0 \%$; 95\% CI =3,050-9,906; Table 1). Compared to 1976-1978, the wild boar population increased by $58 \%$ (Fig. 2). The results of the sensitivity analysis indicated a population increase of $2-75 \%$ (Table 1 ).

\section{Poaching incentives and frequency of hunted species}

The results of our interview surveys and an earlier study (Ashayeri, 2014) revealed five main categories of incentives for poaching, although we concluded that a poacher's decision to go on a hunting trip was influenced by a combination of incentives. Reported incentives were poverty/ livelihoods, hunting for meat market/trade, pleasure/love of hunting, tradition/habits, and hunting for revenge or as a result of conflict with conservation regulations and organizations. Our approach did not facilitate ordinal ranking of incentives based on their importance but showed a mixture of social, economic and policy-related motivations for poaching in the Park (Fig. 3). Our data on law enforcement records for 2007-2014 indicate 113 arrests of poachers, 38 before hunting had taken place. In the remaining 75 cases 113 individuals of eight species had been hunted. Urial accounted for the highest proportion of hunted species (58\%), followed by red deer (12\%) and bezoar goats ( $9 \%)$. 


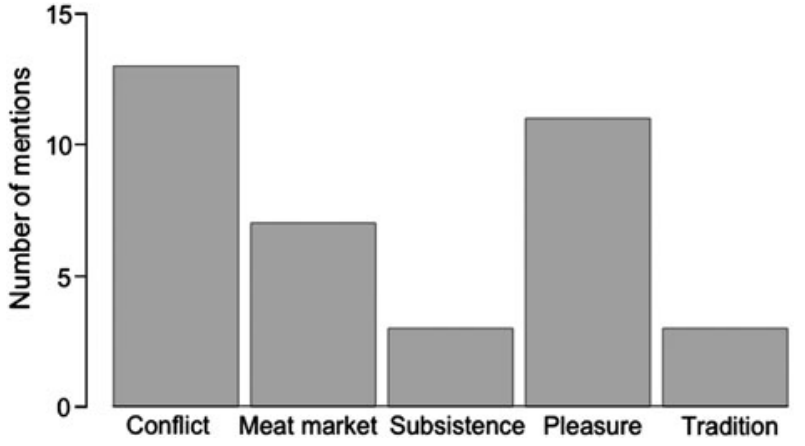

FIG. 3 The frequency with which various incentives for poaching were mentioned by interview respondents in the vicinity of Golestan National Park (Fig. 1).

The rate of poaching relative to population size was highest for red deer $(5.75 \%)$, followed by bezoar goats (1.92\%), urial (1.54\%) and wild boar (0.10\%). Circa $27.4 \%$ of the arrested poachers were not from the villages in the vicinity of the Park.

\section{Discussion}

We estimate there has been a $66-89 \%$ population decline of urial, red deer and bezoar goats in Golestan National Park since the 1970s. These were the preferred species of poachers (authors, unpubl. data) and accounted for the majority of hunted species. Such a trend in the absence of any reported migrations or mass mortalities may represent the effects of poaching in the Park. The fact that the population of wild boar, consumption of which is prohibited by Islam, has increased by $58 \%$ during the same time frame further supports our claim. Poachers avoid hunting this species in the Park (authors, unpubl. data).

The greatest declines were in bezoar goat $(88 \%)$ and red deer $(89 \%)$ populations. Bezoar goat habitat is restricted to patches of cliffs within the Park, where the goats are exposed and vulnerable to poaching. The Park is one of the last population strongholds of red deer in the Caspian forests (Kiabi et al., 2004) but despite dense vegetation and the elusive behaviour of red deer, this species is vulnerable to poaching, especially during the rutting season (authors, unpubl. data). In September and October each year, poachers imitate stag calls to attract deer to within shooting range. Without immediate conservation action both the bezoar goat and the red deer may go extinct in the Park in the near future. The urial population has also declined $(66 \%)$, and the species is almost extirpated from some of its former range in the Park (Decker \& Kowalski, 1972; Ghoddousi et al., 2016a). However, urial still occur in higher densities in the vicinity of the ranger stations (Ghoddousi et al., 2016a). It appears that the lack of regular systematic monitoring coupled with low detection probability of some species may have created an illusion of plenty among park managers, who may underestimate the decline in populations of hunted ungulates.

In Golestan National Park and other Iranian protected areas species living in open landscapes have been routinely monitored by annual total counts. Total counts do not follow a systematic sampling approach and the assumption of observation of all individuals in large areas can rarely be met (Buckland et al., 2001). Moreover, this method does not provide a measure of variance, which is necessary for assessing population trends over time (Suryawanshi et al., 2012). Therefore, it is necessary to adopt monitoring methods that are suitable for rugged landscapes and are sufficiently robust to detect trends in exploited populations at low densities (Singh \& Milner-Gulland, 2011). We used a variety of monitoring methods successfully, and we recommend that the Department of Environment should initiate capacity-building programmes for rangers and invest in the equipment required to conduct similar surveys on a regular basis.

The differences in monitoring methods used in our study and those used to gather historical data are a potential source of bias. However, we are not aware of any other systematic surveys of these species since the establishment of the Park (Decker \& Kowalski, 1972; Kiabi, 1978; Kiabi et al., 2004). Although our camera trapping was designed to target leopards Panthera pardus (Hamidi et al., 2014), we assume it did not produce a major bias, as movement patterns of herbivores are independent of those of carnivores (Cusack et al., 2015). Moreover, randomized encounter modelling of data for red deer and wild boar produced comparable results to other tested methods (Ghoddousi et al., 2016b; Soofi et al., 2017).

Our results demonstrate that conservation laws and enforcement measures have failed to stop poaching since the 1970 s and therefore require reconsideration. We identified a combination of economic and non-economic incentives for poaching of ungulates in the Park, which may guide the selection of appropriate anti-poaching schemes. The variety of incentives to poach suggests that single policies are unlikely to succeed in deterring poaching, and that a combination of approaches is therefore required (Duffy et al., 2016). Poverty and the existence of a market for meat can be considered economic incentives, and creating alternative livelihoods for local communities is a common approach to tackle poaching stemming from such economic incentives (Duffy et al., 2016). However, subsistence poachers normally lack the skills, education and cultural capacities required for employment in many sectors (Nuno et al., 2013). Thus, integrated conservation and development projects could potentially explore livelihood opportunities in developing ecotourism or facilitating the establishment of community-based reserves, benefiting from poachers' local ecological knowledge. Awareness-raising campaigns against consumption of wild meat in urban areas could be 
considered, to target the demand side (Challender \& MacMillan, 2014). In addition, the distribution and efficiency of law enforcement efforts in Golestan National Park should be improved (Ghoddousi et al., 2016a).

The existence of hunting incentives related to tradition and pleasure suggests that alternative livelihood programmes alone may fail to address the poaching problem (Waylen et al., 2009), but community outreach programmes aimed at building trust, awareness, motivation and opportunities have proven to be influential in controlling poaching in South-east Asia (Steinmetz et al., 2014). As the limited number of hunting permits issued annually by the Department of Environment is insufficient to satisfy demand, establishing community-based reserves could provide legal hunting opportunities for local communities. Integrated conservation and development programmes could investigate opportunities for creating such reserves.

As in a previous study in Iran (Ashayeri \& Newing, 2012), conflict with conservation bodies and regulations was stated to be an incentive for poaching. The non-participatory and top-down approach to protected area management (Zendehdel et al., 2010), coupled with hostile encounters between rangers and local communities, causes conflict between the two parties. Additionally, hiring non-local rangers may overlook local ecological knowledge, leave local communities out of decision-making and cause conflict between local communities and conservation authorities. Nevertheless, we presume that conflict may exacerbate poaching but is not a root cause of it.

The future of hunted species in Golestan National Park and protected areas elsewhere in Iran is unclear. We recommend that the Department of Environment should adopt participatory conservation strategies, improve law enforcement practices and cooperate with international experts in resolving the poaching problem nationwide.

\section{Acknowledgements}

We acknowledge the support of the Iranian Department of Environment, the Golestan provincial office of the Department of Environment, and the management of Golestan National Park. We appreciate the cooperation of the Persian Wildlife Heritage Foundation in granting access to their camera-trap and social survey data and for providing logistical support. This study would not have been possible without the collaboration of rangers, local guides and volunteers. AG was funded by the German Academic Exchange Service (DAAD) and Panthera's Kaplan Graduate Award, and MS was funded by Erasmus Mundus/SALAM. We acknowledge Turkmen Ecolodge for hosting the focus group meeting with local poachers, and we thank K. Seyed Emami, M. Festa-Bianchet and an anonymous reviewer for their feedback.

\section{Author contributions}

AG, MS, AKH, SA, LE and MW conceived and designed the research. AG, MS, AKH, SA, LE and SG conducted the surveys. AG, MS, SA and LE analysed data. AG, MS, AKH, SA, LE, JS, IK, BHK and MW wrote the article.

\section{References}

Akнani, H. (2005) The Illustrated Flora of Golestan National Park, Iran, Volume 1. Tehran University Press, Tehran, Iran.

Ashayeri, S. (2014) 2nd Phase of Conservation of Leopard Project in Golestan National Park; Social Research. Unpublished report. Persian Wildlife Heritage Foundation, Tehran, Iran.

Ashayeri, S. \& Newing, H. (2012) Meat, markets, pleasure and revenge: multiple motivations for hunting in Bamu National Park, Fars Province, Iran. Parks, 18, 125-133.

Buckland, S.T., Anderson, D.R., Burnham, K.P., LaAke, J.L., Borchers, D.L. \& Thomas, L. (2001) Introduction to Distance Sampling: Estimating Abundance of Biological Populations. Oxford University Press, Oxford, UK.

Challender, D.W.S. \& MacMillan, D.C. (2014) Poaching is more than an enforcement problem. Conservation Letters, 7, 484-494.

Cusack, J.J., Dickman, A.J., Rowcliffe, J.M., Carbone, C., Macdonald, D.W. \& Coulson, T. (2015) Random versus game trail-based camera trap placement strategy for monitoring terrestrial mammal communities. PLoS ONE, 10(5), e0126373.

Decker, E. \& Kowalski, G.J. (1972) The Behavior and Ecology of the Urial Sheep. Unpublished report. Colorado State University, Fort Collins, USA.

Duffy, R., St John, F.A.V., Büscher, B. \& Brockington, D. (2016) Toward a new understanding of the links between poverty and illegal wildlife hunting. Conservation Biology, 30, 14-22.

Firouz, E. (2005) The Complete Fauna of Iran. I.B. Tauris \& Co, London, UK.

Ghoddousi, A., Hamidi, A.Kh., Soofi, M., Khorozyan, I., Kiabi, B.H. \& WAltert, M. (2016a) Effects of ranger stations on predator and prey distribution and abundance in an Iranian steppe landscape. Animal Conservation, 19, 273-280.

Ghoddousi, A., Soofi, M., Hamidi, A.Kh., Lumetsberger, T., Egli, L., Khorozyan, I. et al. (2016b) Assessing the role of livestock in big cat prey choice using spatiotemporal availability patterns. PLoS ONE, 11(4), e0153439.

Hamidi, A.Kh., Ghoddousi, A., Soufi, M., Ghadirian, T., Jowkar, H. \& Ashayeri, S. (2014) Camera trap study of Persian leopard in Golestan National Park, Iran. Cat News, 6o, 12-14.

Hilborn, R., Arcese, P., Borner, M., Hando, J., Hopcraft, G., Lогвоокі, M. et al. (2006) Effective enforcement in a conservation area. Science, 314, 1266.

IUCN (2016) The IUCN Red List of Threatened Species v. 2016. Http:// www.iucnredlist.org [accessed 15 May 2016].

Jachmann, H. \& Billiouw, M. (1997) Elephant poaching and law enforcement in the Central Luangwa Valley, Zambia. Journal of Applied Ecology, 34, 233-244.

Karami, M., Hemami, M.R. \& Groves, C.P. (2002) Taxonomic, distributional and ecological data on gazelles in Iran. Zoology in the Middle East, 26, 29-36.

KiABI, B.H. (1978) Ecology and management of maral (Cervus elaphus maral) in northeastern Iran, 1976-1978. PhD thesis. Michigan State University, East Lansing, USA.

Kiabi, B.H., Ghaemi, R.A., Jahanshahi, M. \& Sassani, A. (2004) Population status, biology and ecology of the maral, Cervus elaphus 
maral, in Golestan National Park, Iran. Zoology in the Middle East, $33,125-138$.

Kolahi, M., Sakai, T., Moriya, K. \& Makhdoum, M.F. (2012) Challenges to the future development of Iran's protected areas system. Environmental Management, 50, 750-765.

Milner-Gulland, E.J., Bennett, E.L. \& The SCB 2002 Annual Meeting Wild Meat Group (2003) Wild meat: the bigger picture. Trends in Ecology \& Evolution, 18, 351-357.

Milner-Gulland, E.J. \& Leader-Williams, N. (1992) A model of incentives for the illegal exploitation of black rhinos and elephants: poaching pays in Luangwa Valley, Zambia. Journal of Applied Ecology, 29, 388-401.

Milner-Gulland, E.J. \& Rowcliffe, J.M. (2007) Conservation and Sustainable Use: A Handbook of Techniques. Oxford University Press, Oxford, UK.

Moore, P.D. (1976) Conservation in Iran. Nature, 260, 359-36o.

Newing, H. (2011) Conducting Research in Conservation: A Social Science Perspective. Routledge, London, UK.

Nichols, J., Hines, J.E., Sauer, J.R., Fallon, F.W., Fallon, J.E. \& Heglund, P.J. (2000) A double-observer approach for estimating detection probability and abundance from point counts. The Auk, $117,393-408$.

Nuno, A., Bunnefeld, N., Naiman, L.C. \& Milner-Gulland, E.J. (2013) A novel approach to assessing the prevalence and drivers of illegal bushmeat hunting in the Serengeti. Conservation Biology, 27, 1355-1365.

Podgórski, T., Baś, G., Jędrzejewska, B., Sönnichsen, L. ŚNieżKo, S., JęDRZEJEWSKi, W. \& OKaRMa, H. (2013) Spatiotemporal behavioral plasticity of wild boar (Sus scrofa) under contrasting conditions of human pressure: primeval forest and metropolitan area. Journal of Mammalogy, 94, 109-119.

Rezaei, H.R., Naderi, S., Chintauan-Marquier, I.C., Taberlet, P., Virk, A.T., Naghash, H.R. et al. (2010) Evolution and taxonomy of the wild species of the genus Ovis (Mammalia, Artiodactyla, Bovidae). Molecular Phylogenetics and Evolution, 54, 315-326.

Rowcliffe, J.M., Field, J., Turvey, S.T. \& Carbone, C. (2008) Estimating animal density using camera traps without the need for individual recognition. Journal of Applied Ecology, 45, 1228-1236.

Shams Esfandabad, B., Karami, M., Hemami, M., Riazi, B. \& SADOUGH, M. (2010) Habitat associations of wild goat in central Iran: implications for conservation. European Journal of Wildlife Research, 56, 883-894.

Singh, N.J. \& Milner-Gulland, E.J. (2011) Monitoring ungulates in Central Asia: current constraints and future potential. Oryx, 45, 38-49.

Soofi, M., Ghoddousi, A., Hamidi, A.Kh., Ghasemi, B., Egli, L., Voinopol-SAssu, A. et al. (2017) Precision and reliability of indirect population assessments for the Caspian red deer (Cervus elaphus maral). Wildlife Biology, http://dx.doi.org/10.2981/wlb. 00230 .

Steinmetz, R., Srirattanaporn, S., Mor-Tip, J. \& Seuaturien, N. (2014) Can community outreach alleviate poaching pressure and recover wildlife in South-East Asian protected areas? Journal of Applied Ecology, 51, 1469-1478.

Suryawanshi, K.R., Bhatnagar, Y.V. \& Mishra, C. (2012) Standardizing the double-observer survey method for estimating mountain ungulate prey of the endangered snow leopard. Oecologia, $169,581-590$.

Sutherland, W. (2000) The Conservation Handbook: Research, Management and Policy. Blackwell, Oxford, UK.

Tatin, L., Darreh-Shoori, B.F., Toureng, C., Tatin, D. \& Azmayesh, B. (2003) The last populations of the Critically Endangered onager Equus hemionus onager in Iran: urgent requirements for protection and study. Oryx, 37, 488-491.

Thomas, L., Buckland, S.T., Rexstad, E.A., LaAke, J.L., Strind ber G, S., Hedley, S.L. et al. (2010) Distance software: design and analysis of distance sampling surveys for estimating population size. Journal of Applied Ecology, 47, 5-14.

Waylen, K.A., McGowan, P.J.K. \& Milner-Gulland, E.J. (2009) Ecotourism positively affects awareness and attitudes but not conservation behaviours: a case study at Grande Riviere, Trinidad. Oryx, 43, 343-351.

Zendehdel, K., Rademaker, M., De Baets, B. \& Van Huylenbroeck, G. (2010) Environmental decision making with conflicting social groups: a case study of the Lar rangeland in Iran. Journal of Arid Environments, 74, 394-402.

\section{Biographical sketches}

ARASH GHOdDousi works on poaching mitigation, law enforcement practices, wildlife monitoring techniques and human-wildlife conflict. Maнmood Soofi studies human-wildlife interactions at the landscape level. A MIRHOSSEIN KH. HAMIDI is involved in participatory conservation practices. SHEYDA ASHAYERI conducts research on human dimensions in conservation. LUKAS EGLI investigates interactions between land-use change and biodiversity. SIAVASH GHODDOUSI studies ecotourism and regional development. JULIAN SPEICHER focuses on ecology and management of wild animals in natural and modified habitats. IGOR KHOROZYAN works on human-wildlife conflict and carnivore conservation. BAHRAM H. KIAB I studies relationships between wildlife populations and environmental factors. Matthias Waltert is interested in wildlife conservation research and teaching, and has experience in the Old World tropics and the Middle East. 